\title{
A new carnivorous dinosaur from the Late Jurassic Solnhofen archipelago
}

\author{
Ursula B. Göhlich ${ }^{1} \&$ Luis M. Chiappe ${ }^{2}$
}

Small Late Jurassic theropod dinosaurs are rare worldwide. In Europe these carnivorous dinosaurs are represented primarily by only two skeletons of Compsognathus ${ }^{1,2}$, neither of which is well preserved. Here we describe a small new theropod dinosaur from the Late Jurassic period of Schamhaupten in southern Germany ${ }^{3,4}$. Being exquisitely preserved and complete from the snout to the distal third of the tail, the new fossil is the best-preserved predatory, non-avian dinosaur in Europe. It possesses a suite of characters that support its identification as a basal coelurosaur. A cladistic analysis indicates that the new taxon is closer to maniraptorans than to tyrannosauroids, grouping it with taxa often considered to be compsognathids. Large portions of integument are preserved along its tail. The absence of feathers or feather-like structures in a fossil phylogenetically nested within feathered theropods $s^{5,6}$ indicates that the evolution of these integumentary structures might be more complex than previously thought.

The new Schamhaupten fossil is the second non-avian theropod found in the laminated limestones of the Late Jurassic Solnhofen reef archipelago of Bavaria ${ }^{7}$, after the discovery of the celebrated Compsognathus nearly 150 years ago. Biostratigraphic studies of the Schamhaupten limestones indicate that they are 151-152 million years old $^{3,4,8}$, and are therefore slightly older than those containing Compsognathus and the famous bird Archaeopteryx.

Dinosauria Owen, 1842

Theropoda Marsh, 1881C

Tetanurae Gauthier, 1986

Coelurosauria Huene, 1914

Compsognathidae Marsh, 1882

Juravenator starki gen. et sp. nov.

Etymology. Jura, referring to the Bavarian Jura mountains; plus venator (Latin), a hunter. The species name, starki, honours the family Stark, owner of the Quarry Stark.

Holotype. JME Sch 200 (Jura-Museum Eichstätt), a nearly complete and articulated skeleton missing only the distal third of its tail (Fig. 1). The strong scarring and pitting of the bone surface ${ }^{9}$, the lack of fusion between sacral vertebrae, and the presence of open neurocentral sutures ${ }^{10}$ demonstrate that JME Sch 200 is a juvenile.

Horizon and locality. Silicified, laminated limestone, Late Jurassic, Upper Malm, Late Kimmeridgian, Malm Epsilon 2 (setatumsubzone), Quarry Stark, west of Schamhaupten, Southern Franconian Alb, Bavaria, Germany (see Supplementary Information).

Diagnosis. Small basal coelurosaur (preserved length $65 \mathrm{~cm}$; estimated total length $75-80 \mathrm{~cm}$; see Supplementary Information for measurements) with a small number (eight) of maxillary teeth, no premaxillary-maxillary diastema, posterior serrations on premaxillary teeth, concave rostral margin of the jugal process of the postorbital, relatively long scapula with narrowest portion at neck, and proportionally short feet. Juravenator starki may also be diagnosed by the presence of an antorbital fenestra subequal in length to the orbit and by an abbreviated deltopectoral crest of the humerus, although these features may be related to the early ontogenetic age of the holotype. In addition, Juravenator is unique among basal coelurosaurs in having proximally high manual claws that taper abruptly at midpoint, a ventrally notched premaxillary-maxillary contact, and bow-like zygapophyses in mid-caudal vertebrae; these features are interpreted as autapomorphies.

Description and comparisons. The skull of JME Sch 200 is proportionally large (Fig. 1). It has a moderately long rostrum, elliptical external nares bordered by the premaxilla and nasal, a big antorbital fossa largely perforated by an antorbital fenestra and a small maxillary fenestra, round orbits, a flat cranial roof, and teeth lacking anterior serrations (Fig. 2). The premaxilla bears three, perhaps four, teeth-the penultimate one posteriorly serrated (Fig. 1). The maxillary teeth are more recurved than the premaxillary ones. The lacrimal has the shape of an inverted ' $L$ '. The jugal is slender with a well-developed postorbital ramus and a tapering subtemporal ramus that ends shortly behind the base of the latter. The frontal is large and it participates extensively of the supratemporal fenestra. The parietal is one-third to one-quarter the length of the frontal. The frontal ramus of the T-shaped postorbital is slightly longer than the squamosal ramus and shorter than the jugal ramus. The lower jaw of Juravenator lacks a mandibular foramen, as in the compsognathids ${ }^{11}$ Compsognathus ${ }^{1}$, Sinosauropteryx $x^{12}$, Huaxiagnathus ${ }^{13}$ and Scipiony $x^{14}$ and other basal coelurosaurs such as tyrannosauroids, and its teeth-probably not more than 11 -extend caudally to nearly the end of the upper dentition.

There are eight to ten cervical vertebrae. These have short and low neural spines and, as in compsognathids ${ }^{1,12,13}$, extremely long, hair-like ribs (Fig. 1). The trunk is composed of 13 dorsal vertebrae with distally expanded neural spines, another synapomorphy of compsognathids ${ }^{11-13,15}$. The tail is extremely long-comparisons with Sinosauropteryx indicate that the 44 caudal vertebrae preserved in JME Sch 200 represent about two-thirds of the complete tail. Such an elongated tail is comparable to the tail of Sinosauropteryx and longer than in most other theropods ${ }^{16}$. The caudal centra are elongated and very similar throughout the tail. Their length remains more or less constant until the 17th caudal, when the length of the centra starts increasing. The transition point is around the 14th to 15 th vertebra. The short zygapophyses of the middle caudals have a uniquely hooked morphology (Fig. 1). The chevrons are elongate and rod-like shaped; these bones decrease in length gradually towards the distal end of the tail.

The scapula is slender and elongate (its length is about ten times its width at mid-shaft and $80 \%$ of the length of the femur). This bone has a prominent and subtriangular acromion and a scapular blade 
that gradually expands towards its tip. The glenoid is rimmed and directed caudally. The forelimb is $50 \%$ of the length of the hindlimb (measured along their longest digit and including their corresponding claws)_Juravenator has the longest forelimb among compsognathids. The deltopectoral crest of the humerus is proximodistally very short and triangular in shape. The radius and ulna are straight and about two-thirds the length of the humerus. Metacarpal I is about $40 \%$ of the length of metacarpal II but of about the same width. Metacarpal III is about half the width of metacarpal II and 75\% of its length. The hand of Juravenator carries three robust and clawed digits (Fig. 1) with two (I), three (II) and four (III) phalanges. Digit I is the shortest and digit II the longest. The pelvis consists of a low and straight ilium with rounded and squared-off anterior and posterior ends, respectively. The other elements of the pelvis are of difficult interpretation. The hindlimbs are robust. The femur is $10 \%$ shorter than the tibia, which is similarly shorter than the foot (metatarsal III and digit including claw). Metatarsal III is the longest, followed by metatarsals IV and II. Likewise, pedal digit III is the longest, followed by digits IV, II and I; the phalangeal formula of these digits is 2-3-4-5.

Soft tissue is preserved along the tibiae, and particularly between the 8 th and the 22 nd caudal vertebrae, where it defines the outline of the tail. The latter section allows observation of the skin surface and other soft parts (Fig. 3). The integument of Juravenator is formed of uniformly sized, smooth tubercles (about 15 tubercles per $25 \mathrm{~mm}^{2}$ of preserved tissue) similar in appearance to the small, conical and non-imbricated tubercles of many other non-avian dinosaurs ${ }^{17,18}$. An array of feathers has been discovered among non-avian coelurosaurs ${ }^{6}$. However, the absence of either feathers or skin follicles associated with the preserved integument of Juravenator indicates that at least the central portion of the tail of this coelurosaur was devoid of plumage. The remaining soft tissue is represented by a series of fibres ventral to the haemal arches of the 10th to 14th caudals and parallel to the axis of the tail. These fibres probably represent tendons of the hypaxial musculature and ligaments of the tail ${ }^{19}$, as interpreted for similar soft parts associated with the skeleton of Scipionyx ${ }^{14}$, although they could also correspond to bundles of subcutaneous collagen fibres ${ }^{20}$.

A cladistic analysis of 35 theropod taxa (Supplementary Information) clusters Juravenator with a diversity of other basal, smallbodied coelurosaurs of Late Jurassic to Early Cretaceous age. When the analysis is conducted with the exclusion of largely incomplete taxa, Juravenator nests together with compsognathids such as Compsognathus, Sinosauropteryx and Huaxiagnathus (Fig. 4). This condensed analysis recovers a monophyletic Compsognathidae and supports the placement of Juravenator within this clade.

The discovery of feathery integumentary coverings in a variety of coelurosaurs (for example, tyrannosauroids, compsognathids, therizinosauroids, oviraptorosaurs, alvarezsaurids and dromaeosaurids) has cemented the notion that feathers are a synapomorphy of this entire clade $\mathrm{e}^{5,6}$. Thus, the absence of feathers in Juravenator, a

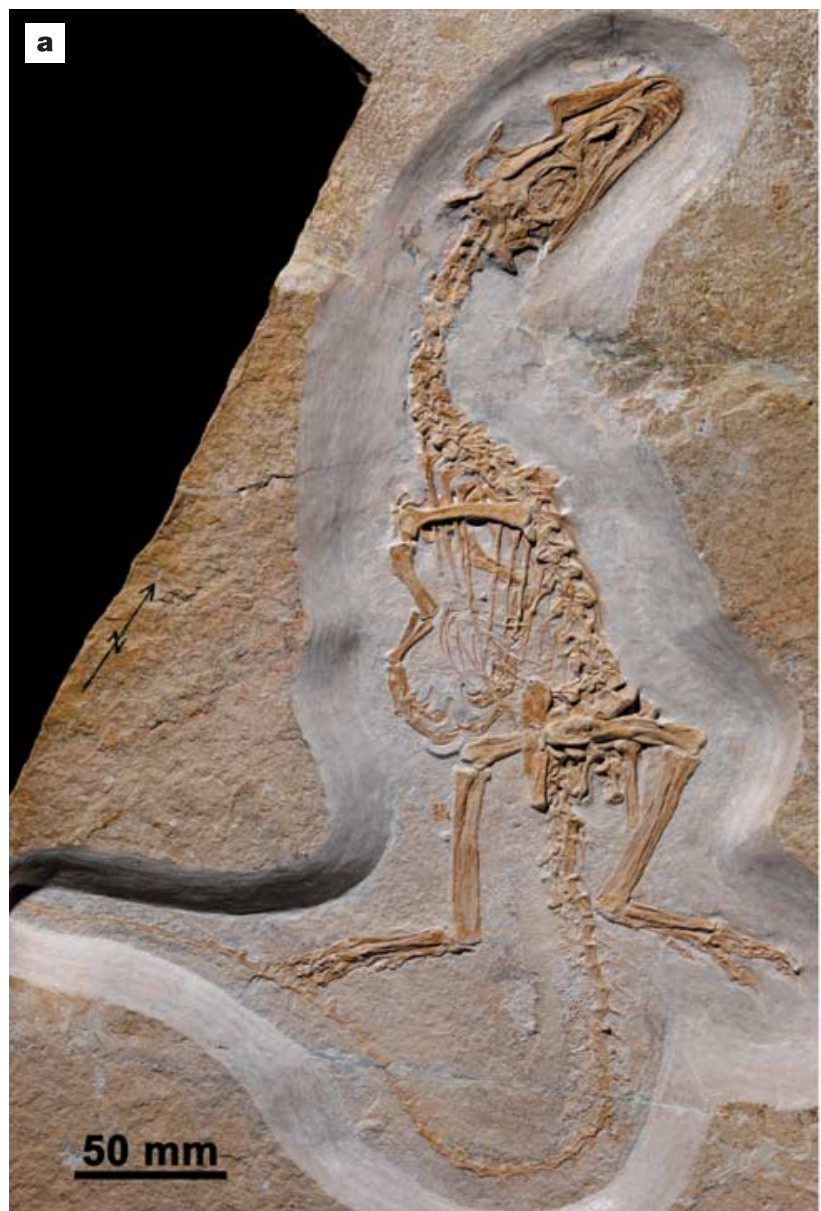

Figure 1 | Holotype of Juravenator starki. a, Specimen photographed under normal light. $\mathbf{b}$, The presence of 'hair-like' cervical ribs (inset 1) is synapomorphic of Compsognathidae. The proximally high manual claws that taper abruptly at their midpoint (inset 2) and bow-like zygapophyses of mid-caudal vertebrae (inset 3 ) are regarded as autapomorphies of Juravenator starki. The serrated premaxillary teeth (inset 4) also distinguish

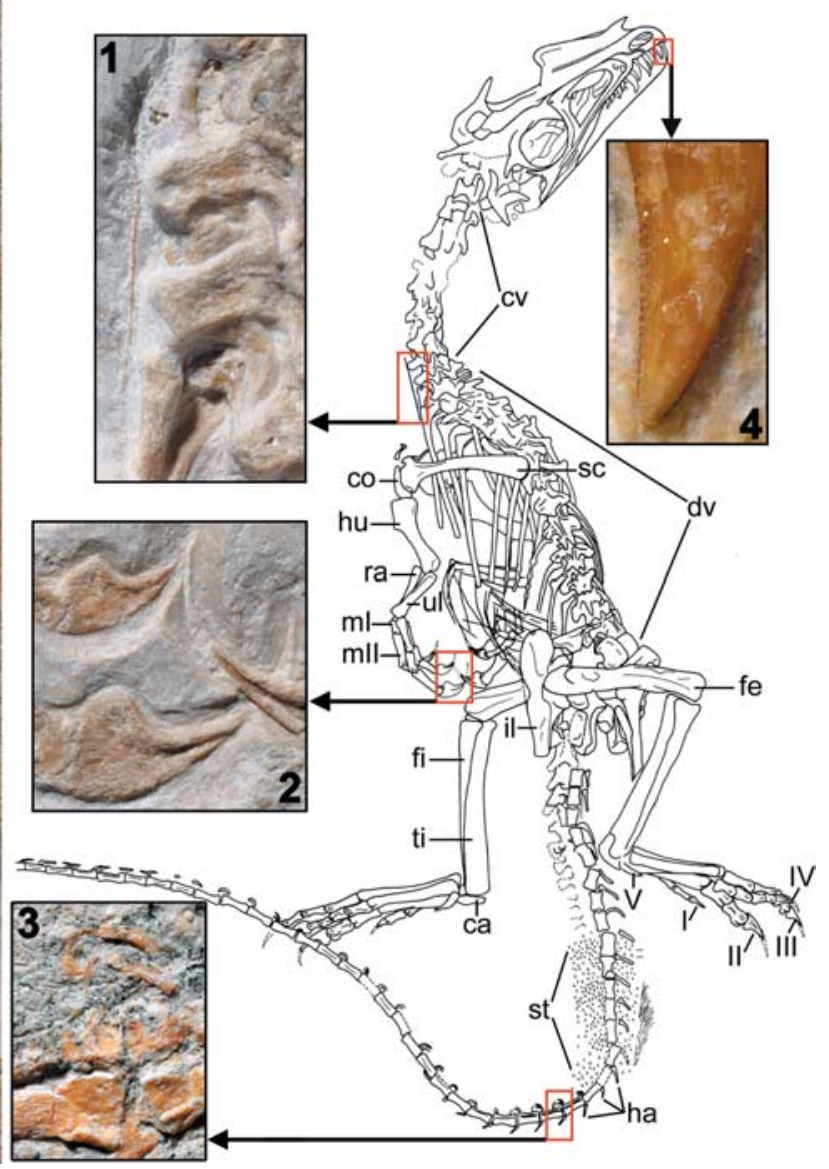

this taxon from most other basal coelurosaurs. Abbreviations: ca, calcaneus; co, coracoid; cv, cervical vertebrae; $\mathrm{dv}$, dorsal vertebrae; fe, femur; fi, fibula; ha, haemal arches; hu, humerus; il, ilium; mI, metacarpal I; mII, metacarpal II; ra, radius; sc, scapula; st, soft tissue; ti, tibia; ul, ulna; I-IV, pedal digits I-IV; V, metatarsal V. 

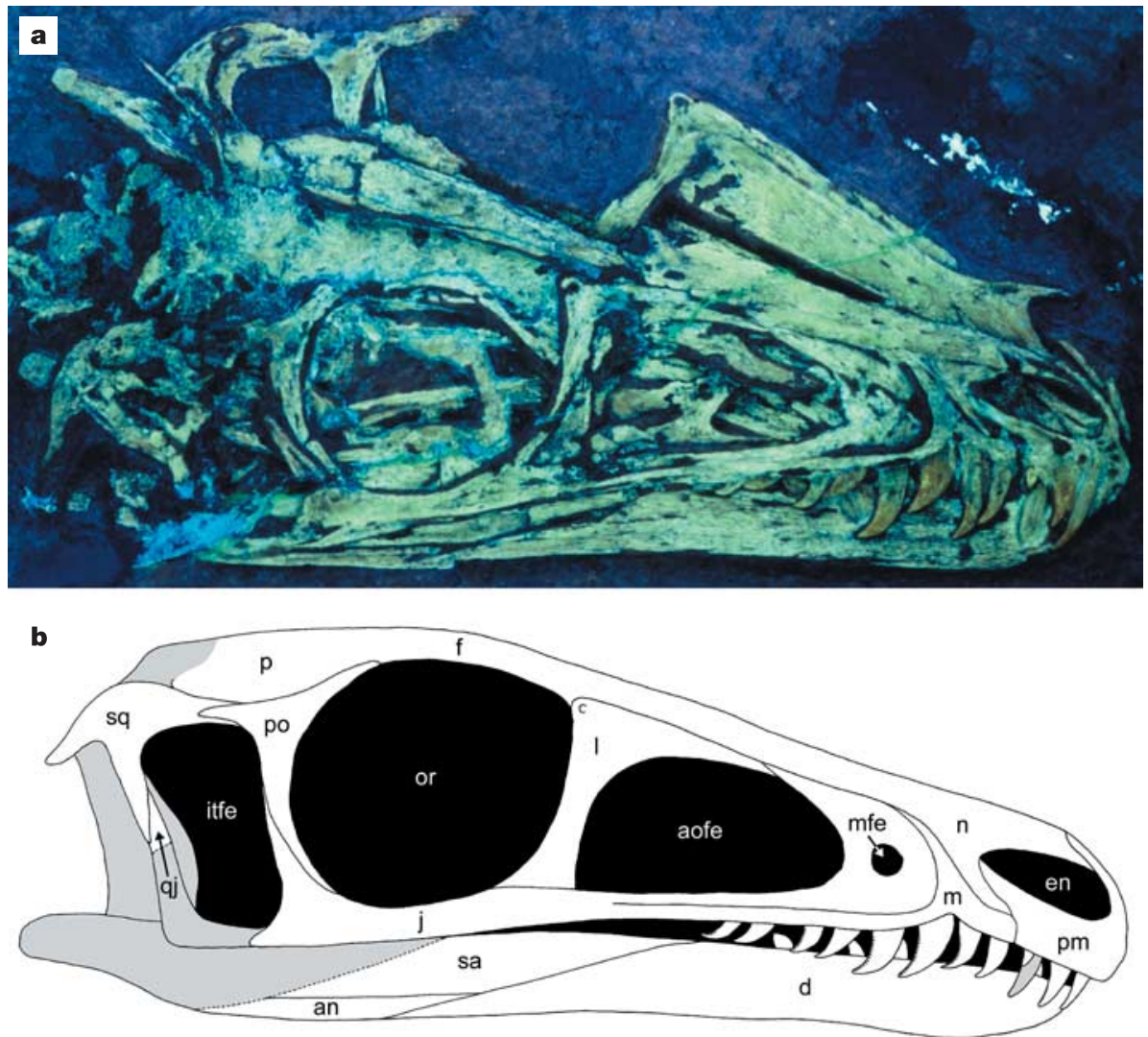

\section{$10 \mathrm{~mm}$}

Figure 2 | Skull and mandible of Juravenator starki. a, Specimen photographed under ultraviolet light. $\mathbf{b}$, As reconstructed (shaded areas show missing portions). Abbreviations: an, angular; aofe, antorbital fenestra; d, dentary; en, external naris; f, frontal; itfe, infratemporal fenestra; j, jugal; l, lacrimal; m, maxilla; mfe, maxillary fenestra; $n$, nasal; or, orbit; $p$, parietal; pm, premaxilla; po, postorbital; qj, quadratojugal; sq, squamosal; sa, surangular.
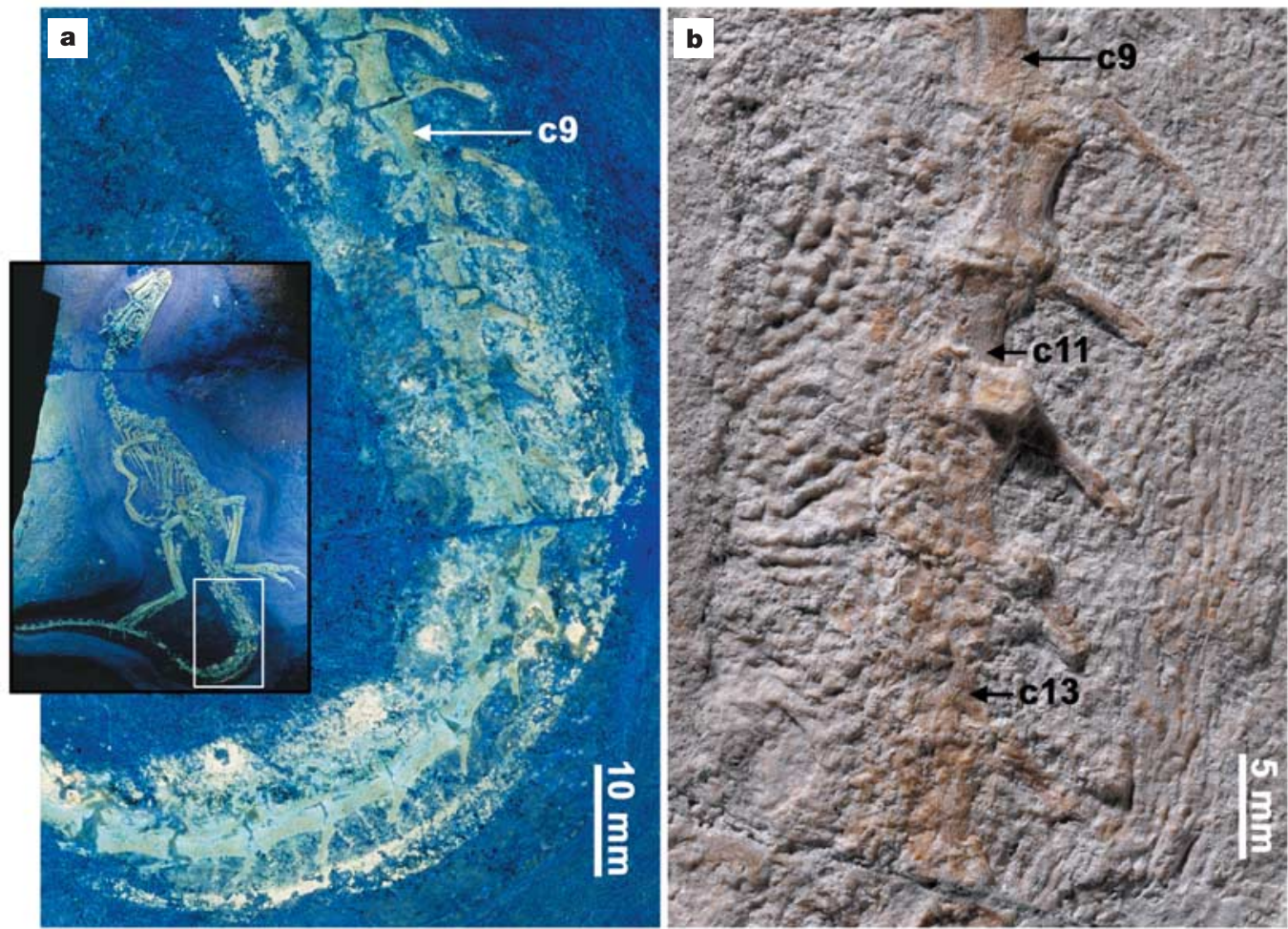

Figure 3 | Integument of Juravenator starki. a, Specimen photographed under ultraviolet light. b, Specimen photographed under normal light. Abbreviations: c9, c11 and c13, caudal vertebrae 9, 11 and 13 . 


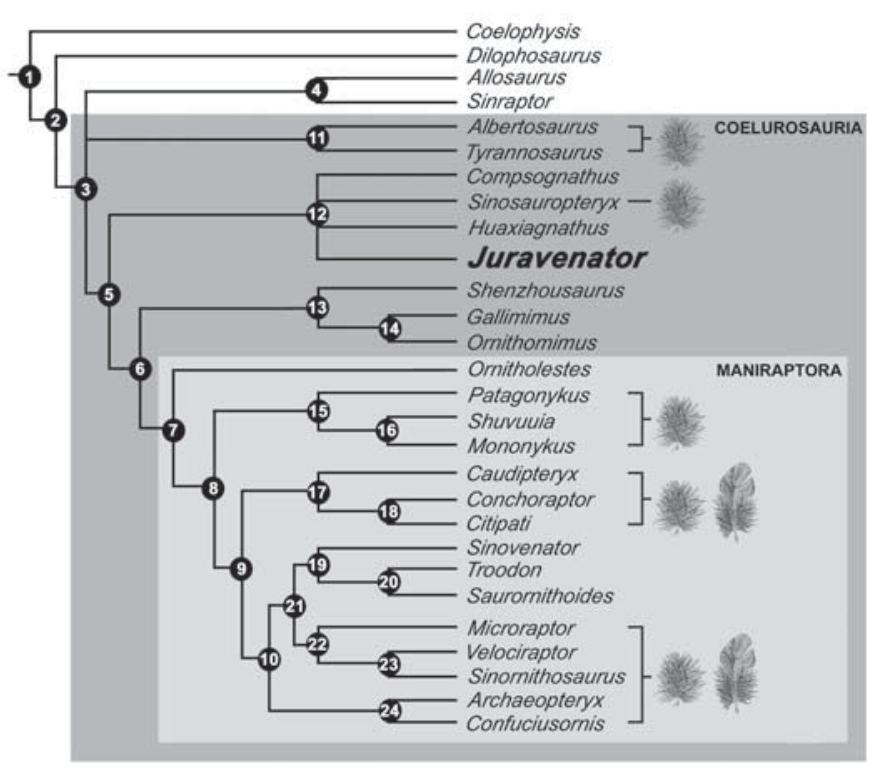

Figure 4 | Strict consensus cladogram. The eight most parsimonious trees (length 497, consistency index 0.45, retention index 0.65 ) for 28 theropod taxa, including Juravenator starki and 189 variables, are shown (see Supplementary Information). In spite of lacking feathers in the preserved integumentary portions, Juravenator starki is grouped together with coelurosaur clades known for having feathery coverings ${ }^{6}$. Plumulaceous and/or pennaceous feathers have been discovered in taxa assigned to Tyrannosauroidea (namely Dilong ${ }^{21}$; in this cladogram, tyrannosauroids are represented by the more advanced Tyrannosaurus and Albertosaurus), Compsognathidae (namely Sinosauroptery $x^{12,16}$ ), Alvarezsauridae (namely Shuvuuia $^{23}$ ), Oviraptorosauria (namely Caudiptery $x^{24}$ ), Dromaeosauridae (namely Microraptor ${ }^{25}$ and Sinornithosaurus ${ }^{26}$ ) and Aves (namely Archaeopteryx and Confuciusornis) ${ }^{28}$.

taxon otherwise nested within feathered coelurosaurs, is noteworthy (Fig. 4). The extent to which feathers covered the body of these non-avian dinosaurs is not well known for some taxa (for example, the tyrannosauroid Dilong ${ }^{21}$, the therizinosauroid Beipiaosaurus ${ }^{22}$, and the alvarezsaurid Shuvuuia ${ }^{6,23}$ ) but complete specimens of Sinosauroptery $x^{12,16}$, the oviraptorosaur Caudiptery $x^{23}$, and several dromaeosaurids ${ }^{24-26}$ indicate that the body of these animals was for the most part feathered. The fact that Juravenator lacks any evidence of feathers in portions of integument otherwise feathered in these coelurosaurs indicates that these animals may have differed greatly in the extension of their feathery covering. However, the role of ontogeny and seasonality in the development of the plumage of these dinosaurs remains uncertain, and the possibility cannot be ruled out that feathers evolved more than once or became lost in taxa such as Juravenator (Fig. 4).

The exquisitely preserved skeleton of Juravenator starki is the most complete non-avian theropod so far discovered in Europe, adding to the diversity of dinosaurs from this continent and in particular to the meagre record of Late Jurassic small theropods ${ }^{27}$. Its discovery sheds light on a poorly known segment of coelurosaur history and indicates that the evolution of feathers in theropods might have been more complex than previously envisaged.

\section{Received 1 September 2005; accepted 10 January 2006.}

1. Ostrom, J. H. The osteology of Compsognathus longipes Wagner. Zitteliana 4, 73-118 (1978).

2. Bidar, A., Demay, L. \& Thomel, G. Compsognathus corallestris, nouvelle espèce de dinosaurien théropode du Portlandien de Canjuers (Sud-Est de la France). Extr. Ann. Mus. Hist. Natur. Nice I, 3-34 (1972).
3. Viohl, G. \& Zapp, M. Schamhaupten, an outstanding fossil-lagerstätte in a silicified plattenkalk (Kimmeridgian-Tithonian Boundary, Southern Franconian Alb, Bavaria). Zitteliana B 26, 27 (2005).

4. Renesto, S. \& Viohl, G. A sphenodontid (Reptilia, Diapsida) from the Late Kimmeridgian of Schamhaupten (Southern Franconian Alb, Bavaria, Germany) Archaeopteryx 15, 27-46 (1997).

5. Chiappe, L. M. \& Dyke, G. J. The Mesozoic radiation of birds. Annu. Rev. Ecol. Syst. 33, 91-124 (2002).

6. Norell, M. A. \& Xu, X. Feathered dinosaurs. Annu. Rev. Earth Planet. Sci. 33, 277-299 (2005).

7. Barthel, K. W., Swinburne, N. H. M. \& Conway Morris, S. Solnhofen-A Study in Mesozoic Palaeontology (Cambridge Univ. Press, Cambridge, 1990).

8. Viohl, G. Fund eines neuen kleinen Theropoden. Archaeopteryx 17, 15-19 (1999).

9. Sanz, J. L. et al. A nestling bird from the Lower Cretaceous of Spain: implications for avian skull and neck evolution. Science 276, 1543-1546 (1997).

10. Brochu, C. A. Closure of neurocentral sutures during crocodilian ontogeny: implications for maturity assessment in fossil archosaurs. J. Vertebr. Paleontol. 16, 49-62 (1996)

11. Peyer, K. A Reevaluation of the French Compsognathus of the Tithonian of South-eastern France and its Phylogenetic Relationship with Other Compsognathids and Coelurosaurs in General. Thesis, Muséum National d'Histoire Naturelle, Paris (2004).

12. Currie, P. J. \& Chen, P.-J. Anatomy of Sinosauropteryx prima from Liaoning, northeastern China. Can. J. Earth Sci. 38, 1705-1727 (2001).

13. Hwang, S. H., Norell, M. A., Qiang, J. \& Keqin, G. A large compsognathid from the Early Cretaceous Yixian Formation of China. J. Syst. Paleontol. 2, 13-30 (2004).

14. Dal Sasso, C. \& Signore, M. Exceptional soft-tissue preservation in a theropod dinosaur from Italy. Nature 392, 383-387 (1998).

15. Naish, D., Martill, D. M. \& Frey, E. Ecology, systematics and biogeographical relationships of dinosaurs, including a new theropod, from the Santana Formation (?Albian, Early Cretaceous) of Brazil. Hist. Biol. 16, 57-70 (2004).

16. Chen, P.-J., Dong, Z.-M. \& Zhen, S.-N. An exceptionally well-preserved theropod dinosaur from the Yixian Formation of China. Nature 391, 147-152 (1998).

17. Czerkas, S. in Encyclopedia of Dinosaurs (eds Currie, P. J. \& Padian, K.) 669-675 (Academic, San Diego, 1997).

18. Chiappe, L. M. et al. Sauropod dinosaur embryos from the Late Cretaceous of Patagonia. Nature 396, 258-261 (1998).

19. Frey, E. Anatomie des Körperstammes von Alligator mississippiensis Daudin. Stuttg. Beitr. Naturkd. A 424, 1-106 (1988).

20. Lingham-Soliar, T. Evolution of birds: ichthyosaur integumental fibers conform to dromaeosaur protofeathers. Naturwissenschaften 90, 428-432 (2003).

21. $\mathrm{Xu}, \mathrm{X}$. et al. Basal tyrannosauroids from China and evidence for protofeathers in tyrannosauroids. Nature 431, 680-684 (2004).

22. Xu, X., Tang, Z.-L. \& Wang, X.-L. A therizinosauroid dinosaur with integumentary structures from China. Nature 399, 350-354 (1999).

23. Schweitzer, M. H. et al. Beta-keratin specific immunological reactivity in feather-like structures of the Cretaceous alvarezsaurid, Shuvuuia deserti. J. Exp. Zool. 285, 146-157 (1999)

24. Ji, Q., Currie, P. J., Norell, M. A. \& Ji, S.-A. Two feathered dinosaurs from northeastern China. Nature 393, 753-761 (1998).

25. Xu, X., Wang, X.-L. \& Wu, X.-C. A dromaeosaurid dinosaur with a filamentous integument from the Yixian Formation of China. Nature 401, 262-266 (1999).

26. Xu, X. et al. Four-winged dinosaurs from China. Nature 421, 335-340 (2003).

27. Weishampel, D. B., Dodson, P. \& Osmólska, H. The Dinosauria 2nd edn (Univ. of California Press, Berkeley, 2004).

28. Chiappe, L. M. \& Witmer, L. M. Mesozoic Birds: Above the Heads of Dinosaurs (Univ. of California Press, Berkeley, 2002).

Supplementary Information is linked to the online version of the paper at www.nature.com/nature.

Acknowledgements We thank H. Weiss and K.-D. Weiss for discovery of the specimen, P. Völkl for its preparation, H. Tischlinger and G. Janssen for photography, M. Kölbl-Ebert and F. Stark for access to the specimen, and E. Frey, D. Goujet, S. Hwang, R. Leinfelder, O. Rauhut, M. Röper, G. Viohl, P. Wellnhofer and W. Werner for providing access to specimens, for logistics, and/or for discussions. This research was made possible by the Humboldt Foundation, and was also supported by the Jurassic Foundation, European Commission's Research Infrastructure Action-Synthesys Program, Antorchas Foundation, Bavarian State Collection for Paleontology and Geology, Department for Geoand Environmental Sciences (Munich University), DFG, Jura Museum, and Natural History Museum of Los Angeles County.

Author Information Reprints and permissions information is available at npg.nature.com/reprintsandpermissions. The authors declare no competing financial interests. Correspondence and requests for materials should be addressed to L.M.C. (chiappe@nhm.org). 